\title{
A organização do conhecimento arquivístico: perspectivas de renovação a partir das abordagens científicas canadenses ${ }^{1}$
}

Natália Bolfarini Tognoli

\begin{abstract}
Bacharel em Arquivologia. Doutoranda e Mestre em Ciência da Informação pelo Programa de PósGraduação em Ciência da Informação, Faculdade de Filosofia e Ciências, Universidade Estadual Paulista. Bolsista da Fundação de Amparo à Pesquisa do Estado de São Paulo - FAPESP
\end{abstract}

José Augusto Chaves Guimarães

Professor Titular do Programa de PósGraduação em Ciência da Informação, Faculdade de Filosofia e Ciências, Universidade Estadual Paulista.

Desde o final do século $X X$, as novas formas de produção documental e as novas tecnologias de informação apresentadas à Arquivística têm levado os profissionais da informação a repensar os conceitos e princípios arquivísticos postulados nos antigos manuais da área. Nesse contexto, destaca-se a produção arquivística canadense, que transformou o país em solo fértil para as discussões que circundam a disciplina na contemporaneidade, representando muito bem as necessidades colocadas pelos novos meios de produção documental aos arquivistas na sociedade da informação, redescobrindo princípios e (re) definindo conceitos, métodos e critérios para a criação, manutenção e uso de documentos em meio tradicional e eletrônico. Foi notadamente na década de 1980, que um novo paradigma se enunciou na área e, a partir dele, três correntes emergiram: a Arquivística Integrada enunciada pela Escola de Québec - que propõe a reintegração da disciplina por meio do ciclo vital dos documentos e uma possível aproximação com a Ciência da Informação, graças à incorporação do termo

\footnotetext{
${ }^{1}$ Este trabalho encontra fundamento, dentre outros, na dissertação de mestrado em Ciência da Informação, defendida por Natália Bolfarini Tognoli, na UNESP-Marília, em 2010, sob orientação do Programa de PósGraduação e com financiamento da Fundação de Amparo à Pesquisa do Estado de São Paulo - FAPESP.
} 
informação orgânica registrada, como substituição ao termo documento de arquivo; a Arquivística Funcional ou Pós-Moderna, enunciada por Terry Cook - que propõe uma renovação e reformulação dos princípios e conceitos originais da disciplina, adotando a corrente Pós-moderna como pano de fundo; e a Diplomática Arquivística, enunciada primeiramente na Itália por Paola Carucci, mas desenvolvida e reformulada na América do Norte por Luciana Duranti, que busca, por meio do estudo da Diplomática, estabelecer critérios para a crítica textual dos documentos contemporâneos, garantindo ao método diplomático um posto fundamental na Arquivística contemporânea. A vista de tais aspectos, analisa-se, comparativamente, o universo epistemológico dessas três abordagens arquivísticas canadenses, enquanto perspectivas emergentes para a construção de uma disciplina contemporânea, capaz de dar conta dos novos processos de produção, organização e uso da informação orgânica registrada.

Palavras-Chave: Organização do conhecimento arquivístico; Arquivística integrada; Arquivística funcional; Diplomática contemporânea.

\section{The Archival Knowledge Organization: some renewal perspectives from the Canadian scientific approaches}

Since the late twentieth century, the impact of new forms of document production as well as the huge growth of information technologies has led information professionals to rethink the traditional archival concepts and principles expressed in old Archival Science manuals. In this context, the Canadian scientific archival production can be highlighted. It gave the country the status of fertile ground for discussions on Archivistics and led to the "reshaping" of traditional archival principles and, as a consequence, (re)defined concepts, methods and criteria for the creation, maintenance and use of documents in electronic and traditional environments. In the 80's, especially, a new paradigm was enunciated in the area and three approaches have emerged: Integrated Archival Science, enunciated by the Québec group which proposed the reintegration of the discipline through document vital cycle and a proximity with Information science due to the 
incorporation of the term organic information; Functional Archival Science or Postmodern Archival Science, enunciated by Terry Cook which proposed the renewal and reformulation of Archival Science principles and concepts, adopting the Post Modernist current as background; and Contemporary? first enunciated in Italy by Paola Carucci and deeply developed and reformulated in North America by Luciana Duranti which aims, through Diplomatics studies, to establish criteria for records critics, ensuring the diplomatic method a safe place in Contemporary Archival Science. Considering such scientific scenarios, this paper aims to establish a comparative discussion between the epistemological foundations of these three Canadian Archival approaches while emergent perspectives to build a contemporary archival discipline capable of facing the new processes of production, organization and use of recorded organic information.

Keywords: Archival knowledge organization; Integrated archival science; Functional archival science; Contemporary diplomatics.

Recebido em 28.04.2010 Aceito em 10.01.2011

\section{Introdução}

A Ciência da Informação (CI), enquanto área que estuda, por excelência, a produção, organização e uso da informação registrada, emerge com uma base conceitual específica, enquanto seus fazeres se materializam nas atividades profissionais da área da informação, especificamente na Arquivística e na Biblioteconomia.

Como destaca Guimarães (2008, p. 39), "pode-se dizer que a CI nutre, teórica e metodologicamente, os fazeres arquivístico e bibliotecário enquanto a Arquivologia e a Biblioteconomia atuam como campos de aplicação e validação das teorias e metodologias oriundas da Ciência da Informação".

No tocante a essas atividades profissionais, destaca-se, aqui, a Arquivística, disciplina desenvolvida historicamente a partir de seu fazer e que encontrou, no século XIX, uma dimensão própria, a partir das reflexões geradas com a publicação de manuais específicos, cujo objetivo residia no estabelecimento de regras e princípios para a organização dos arquivos.

Esses manuais tornaram-se verdadeiras "bíblias" para os arquivistas modernos e seus princípios e conceitos têm sido constantemente discutidos no século XXI, de forma a garantir a consistência da Arquivística na contemporaneidade. No entanto, seus preceitos 
necessitam ser repensados e reformulados, dada a inédita quantidade de documentos gerados nos dias de hoje, inclusive em meio eletrônico, uma vez que as novas formas de produção documental e as novas tecnologias de informação apresentadas à sociedade, têm levado os arquivistas a repensar o papel na chamada "era da informação", assim como os princípios arquivísticos postulados nos manuais da área.

Nesse sentido, destacam-se os estudos realizados no Canadá, a partir do final da década de 80, quando um novo paradigma emerge, enunciado por Hugh Taylor. A partir daí, os arquivistas trabalham em direção à "redescoberta" do princípio da proveniência, que passa a ser virtual e dinâmico, focando a análise no processo de criação dos documentos.

Em meio a esse cenário de ruptura paradigmática, de reformulação e reinterpretação de princípios e métodos, relativamente às perspectivas de organização do conhecimento arquivístico, três abordagens distintas emergiram em solo canadense no final da década de 1980: a Arquivística Integrada, a Arquivística Pós-Moderna e a Diplomática Arquivística.

Face ao exposto, este artigo realiza um estudo sobre essas abordagens emergentes e suas características, apresentando suas contribuições para a sustentação da Arquivística no século XXI.

\section{As abordagens emergentes: fundamentação e contexto histórico}

As abordagens que emergiram no Canadá, estão fundamentadas em um mesmo contexto histórico: no momento de ruptura enfrentado pela Arquivística no final da década de 1980, quando é enunciado um novo paradigma, fruto das novas formas de produção documental, experimentadas devido às tecnologias de informação.

Esse contexto proporcionou, ainda, uma mudança no objeto de estudo da área. Antes entendido como um conjunto de documentos produzidos e/ou recebidos por uma pessoa física ou jurídica no desempenho de uma função específica, o objeto da disciplina passa a ser o conjunto de informações orgânicas, devido à expansão e mudanças tecnológicas observadas no final da década de 1980, quando se reconhece a informação como elemento estratégico central nas organizações e no Estado. Neste sentido, podemos entender, ainda, que a Arquivística passa a ter um contato maior, embora ainda tímido, com a Ciência da Informação, à medida que, finalmente, declara, a partir da abordagem quebequense, ter na informação orgânica registrada seu objeto.

O desenvolvimento teórico da Arquivística no Canadá está ligado, também, à necessidade de estabelecer uma identidade canadense, um senso de nacionalismo e patriotismo, perseguidos desde o início do país, enquanto Confederação. Nesse sentido, o país identifica nos documentos um valor social, capaz de fomentar e moldar sua herança cultural. 
Desde os primeiros anos da Confederação (início do século XIX), o Canadá demonstrou forte preocupação com a história do país e, consequentemente, com a herança documental canadense, produzida, muitas vezes, fora de sua esfera geográfica. Os canadenses perceberam que sua identidade poderia ser alcançada por meio da preservação e estudo da história local.

Muitas sociedades convivendo em uma só. Descendentes de nativos, franceses e ingleses procuravam, com o estabelecimento de uma história local, distinguir-se de suas origens exteriores, na tentativa de criar uma memória coletiva própria. Nesse contexto, o Arquivo Nacional do Canadá foi criado após cinco anos da instituição do país como Confederação, conforme destacou Heather MacNeil (1994, p. 134, tradução nossa):

Ao contrário dos Estados Unidos, o Canadá, desde os primeiros dias da Confederação, instituiu uma tradição de envolvimento direto do governo no cuidado e administração de suas fontes históricas e culturais. O envolvimento do setor público nas esferas cultural e social do país estava profundamente inserido na consciência do Canadá.

O papel dos Arquivos Públicos do Canadá como custodiadores da herança documental pública e privada está intimamente ligado a nãotradição do papel de benfeitores privados na constituição da memória do país. Ao contrário dos Estados Unidos, que possuíam benfeitores nas artes e cultura, como Rockefeller e Carnegie, o Canadá contava com poucas iniciativas privadas e, por essa razão, o Estado teve que desempenhar um papel de liderança no estabelecimento da herança cultural do país.

Nasceu assim a fundação para uma visão arquivística canadense distinta, uma visão que compreendia a aquisição de cópias e originais de documentos públicos e privados como uma função arquivística legítima e principal para os Arquivos Públicos, como era chamado. O conceito de arquivos totais, que ainda não havia sido articulado por nome, encontrou suas origens nessa crença do papel central do governo na preservação de documentos históricos de todas as fontes. $O$ núcleo dos arquivos totais encontra-se nessa aceitação da responsabilidade pública para a sociedade e o cidadão (MILLAR, 1998, p. 111, tradução nossa).

O novo sentido dado ao princípio da proveniência, também fundamenta as abordagens. Para tentar compreender o novo processo de produção e organização do conhecimento arquivístico, os arquivistas canadenses têm se esforçado, publicando inúmeros artigos em periódicos da área, trabalhando em direção ao que eles chamam "redescoberta da proveniência". 
O princípio basilar da Arquivística é, então, elevado ao status de "salvador", e sua redescoberta e reinterpretação é fundamental para a compreensão dos processos de criação e organização dos registros e, ainda, para os contextos em que esses documentos foram gerados.

Entendido antes como um princípio físico e estático, seu objetivo era proteger a integridade dos fundos, mantendo-os unidos fisicamente. No entanto, mais do que manter a união dos documentos provenientes de uma mesma fonte criadora, em um fundo específico, o princípio pode ser utilizado para a análise funcional nos contextos e processos de criação dos documentos.

[...] as funções e atividades que os documentos incorporam, os processos e os procedimentos que eles refletem, suas relações com outros tipos de documentos. A aplicação desse conhecimento ao gerenciamento de documentos por todo seu histórico de vida é visto como um meio dos arquivistas forçarem e expandirem seus papeis enquanto administradores e custodiadores de documentos (MACNEIL, 1994, p. 142, tradução nossa).

Esse "redescobrimento" da proveniência leva os arquivistas a entenderem a contextualização do documento, sua função, seu criador, sua forma e seu papel na instituição que o criou.

[...] ao focar-se na 'proveniência, respeito aos fundos, contexto, evolução, inter-relações, ordem' dos documentos, que está, tradicionalmente no centro da nossa profissão e discurso teórico, os arquivistas poderiam mover-se do 'paradigma da informação' para o 'paradigma do conhecimento' (COOK, 1997, p. 36, tradução nossa).

Agora, o princípio deixa de ser estático e passa a ser um princípio dinâmico e funcional, que condiz muito mais com a realidade organizacional em que a estabilidade estrutural desapareceu, e podendo ser utilizado com muito mais valor na era dos documentos eletrônicos, com a dinamicidade caracterizando os processos de criação dos registros.

Ao invés de abandonar 0 pensamento arquivístico os arquivistas canadenses começaram a descobrir (ou redescobrir) a excitação intelectual da informação contextualizada, que era o próprio legado da profissão. Uma grande gama de estudos logo apareceu no Canadá para explorar a informação da proveniência sobre os criadores de documentos, a administração de documentos, e as formas, funções, e características físicas de vários documentos arquivísticos em todos os meios. (COOK, 1997, p. 36, tradução nossa) 
A "redescoberta" da proveniência é defendida por autores como Luciana Duranti, Terry Cook, Hugh Taylor, Laura Millar, Heather MacNeil, David Bearman, Eric Ketelaar, Tom Nesmith, entre outros, e é, portanto, disseminada por todas as abordagens emergentes nesse contexto.

Após traçadas as bases nas quais as abordagens canadenses estão fundamentadas - os desafios propostos pelas novas tecnologias de informação e novas formas de produção de documentos, a enunciação de um novo paradigma e a necessidade de estabelecer uma herança cultural no país, passa-se, agora, a cada uma das abordagens previamente apresentadas.

\subsection{Arquivística integrada: o papel da informação orgânica}

A América do Norte conheceu, nos anos 1950, novos conceitos e novas práticas arquivísticas para o tratamento da massa documental acumulada durante mais de um século pelas administrações públicas.

Essa nova realidade apresentada aos arquivistas gerou uma ruptura na teoria e na prática arquivística, no momento em que separou seu objeto, o documento de arquivo, diferenciando-o para os record managers e o para os archivists. Nesse momento, cabia, portanto, aos record managers gerenciar a documentação corrente e intermediária produzida pelas instituições, enquanto que aos archivists estavam ligados aos documentos que poderiam ser considerados de cunho histórico permanente.

No entanto, a partir dos anos 1980, uma nova abordagem surge no Canadá francês, com a intenção de reintegrar a disciplina, trabalhando novamente com todo o ciclo documental, dos documentos correntes até os permanentes. É a chamada Arquivística Integrada, cujos estudos estão baseados nas realidades europeia dos documentos históricos e norteamericana da gestão documental.

Nesse sentido, a Arquivística Integrada busca uma reintegração da disciplina, focando seus estudos na gestão da informação orgânica e em sua importância para o fortalecimento da disciplina nos séculos XX e XXI.

Essa abordagem integradora foi proposta primeiramente por Couture, Ducharme e Rousseau, no final dos anos 1980, devido às necessidades enfrentadas pelo Arquivo Nacional do Québec em trabalhar com documentos ativos, semi-ativos e históricos.

[...] assiste-se hoje em Québec, a um crescimento gradual do consenso quanto à necessidade funcional e até mesmo estratégica de unir em uma só profissão os profissionais do record management e aqueles da arquivística tradicional, em torno de noções, princípios e métodos comuns [...] (COUTURE; DUCHARME; ROUSSEAU, 1988, p. 53, tradução nossa). 
Aqui, a Arquivística e o arquivista não devem mais ser vistos como simples guardiões da memória histórica e institucional. Eles participam agora, do momento de criação dos documentos ativos, garantindo, também, uma racionalização da informação e de seus processos. A contribuição dos arquivistas para a gestão da informação e a união das profissões em um só profissional "constituem a base da identidade moderna da disciplina" (COUTURE; DUCHARME; ROUSSEAU, 1988, p. 53, tradução nossa).

Nesse contexto, a informação começa a ter um papel mais ativo na disciplina, pois é um elemento fundamental para o funcionamento e desenvolvimento de qualquer organização e, por essa razão, deve ser gerida de forma eficaz.

Os termos informação orgânica e informação não-orgânica são frutos da abordagem quebequense. Aqui, a informação orgânica é definida como aquela que é produzida e/ou recebida no âmbito de uma atividade e a produção de uma ou mais informações orgânicas darão origem aos arquivos da instituição. Já as informações não-orgânicas são aquelas contidas em documentos bibliográficos, como as publicações e os materiais de referências, por exemplo.

Como consequência, a gestão de documentos também dará lugar à gestão da informação orgânica, que desempenhará um papel decisivo, no que tange à organização e disseminação das informações e à rapidez nos processos de tomada de decisão no interior das organizações.

Observa-se, portanto, que ao definir o objeto da Arquivística como a informação orgânica registrada, a abordagem quebequense busca inserir a disciplina na chamada "era da informação", integrando manager e archivist em uma só profissão, de maneira a garantir a sustentação da Arquivística em um novo contexto de produção de informações.

Uma disciplina que quer ser reconhecida socialmente deve se esforçar ao máximo para construir um conjunto de conceitos, teorias e práticas globais, ao invés de fragmentá-los em duas disciplinas 'opostas', como ocorrera até então com a Arquivística tradicional e a gestão de documentos. A proposta dos teóricos do Québec é um ponto de partida para uma consolidação da Arquivística enquanto uma disciplina integrada e autônoma, capaz de oferecer as soluções para os problemas colocados às organizações na era da informação, no que tange à produção e organização de informações orgânicas registradas.

Destaca-se, ainda, que a realidade brasileira constitui uma exceção no tocante ao objeto da disciplina e à aproximação com a Ciência da Informação. No Brasil, os cursos de Arquivística, assim como os de Biblioteconomia, estão inseridos majoritariamente nos departamentos de Ciência da Informação nas Universidades, o que demonstra uma busca por aproximar disciplinas relacionadas, visando a uma construção Interdisciplinar em CI, ao menos, em sua estrutura. Essa visão só é possível a partir do diálogo estabelecido entre as disciplinas, com base na informação registrada. Como bem destacou Smit (2000, p. 28), a relação é estabelecida quando a ênfase passa a ser dada na informação e não apenas no documento. Nesse contexto, "documento e informação 
constituem as duas faces da mesma moeda [..] sendo impossível descolar as faces da moeda" (SMIT, 2000, p. 30).

Desta feita, a realidade arquivística brasileira encontra nos conceitos enunciados pela Arquivística Integrada um espaço de interlocução, uma vez que desde a década de 1970, trabalha com o ciclo vital dos documentos como parte de uma única área, relacionando-se com a CI, à medida que estabelece com ela um diálogo a partir do binômio documento/informação registrado.

A segunda abordagem, tratada nesse trabalho, busca, por meio da reinterpretação dos princípios basilares da área e do foco no processo de produção da informação, renovar a disciplina para que ela possa dar conta do novo contexto apresentado aos arquivistas no final da década de 1980 .

\subsection{Arquivística funcional: uma revisão de princípios}

Assim como Québec, a parte inglesa do Canadá tem respondido muito bem às necessidades colocadas aos arquivistas no século XXI, transformando o solo canadense em terra fértil para as discussões que circundam a Arquivística na contemporaneidade.

Em 1987, o arquivista Hugh Taylor identificou uma mudança paradigmática, como foi apontado por Ketelaar (2000, p. 326, tradução nossa):

Hugh Taylor proclamou e previu a mudança de paradigma. 0 objeto do novo paradigma da ciência arquivística é o que Thomassen chama de "process-bound information", que é a informação gerada pelos processos administrativos e estruturada por esses processos com objetivo de permitir uma recuperação contextual, com o contexto desses processos como ponto de partida.

Para Taylor (1987, p.14, tradução nossa), não se trata apenas de documentos gerados em meios diferentes, de uma forma mais rápida, pois, como destaca:

Nós ficaremos anestesiados e paralisados [...] se continuarmos pensando que tudo o que temos são bits [...] o mesmo texto e imagem se movendo mais rápido e ocupando menos espaço, onde devemos fazer alguns ajustes tecnológicos pra continuar no ramo.

No entanto, é preciso que se esteja consciente da emergência de um novo paradigma, ocasionada pelas mudanças sociais, tecnológicas e profissionais ocorridas nos últimos anos. Com isso, o arquivista deve repensar o papel da informação nas instituições públicas e privadas, em que a máxima "direito à informação" nunca esteve tão em alta. 
As origens de uma Arquivística Funcional ou Pós-moderna residem, justamente, na identificação do novo paradigma enunciado por Taylor e têm seus estudos aprofundados nos textos de Terry Cook, que também admite a obsolescência dos princípios e métodos arquivísticos gerados no século XIX, defendendo seu repensar para a sobrevivência e adaptação da disciplina nos dias atuais.

Nesse contexto de reformulações e reinterpretações conceituais e disciplinares, Cook defende a ideia de uma mudança que englobe agora o contexto sócio-cultural e ideológico de criação dos documentos. Essa visão recai, também, sobre o papel desempenhado pelos registros nesse novo momento. Segundo o autor, este não deve mais ser visto com um objeto estático e sim como um agente ativo na formação da memória humana e organizacional.

A abordagem pós-moderna é fruto desse contexto e trabalha no sentido de reconhecer as relações existentes entre os criadores de documentos, as funções desempenhadas por eles e refletidas nos registros, assim como as convenções narrativas empregadas nesse processo que, de algum modo, irão refletir na herança documental.

Nesse sentido, a abordagem pós-moderna, apoia-se na análise funcional do processo de criação dos documentos - daí o nome Arquivística Funcional - que, segundo Ketelaar (2000, tradução nossa), substitui a arquivística descritiva, uma vez que somente por meio da interpretação funcional do contexto de criação dos documentos pode entender-se a integridade dos fundos e as funções dos documentos de arquivo em seu contexto original.

A análise desse contexto é feita a partir da análise dos criadores de documentos, de cima para baixo, do todo para a peça (top-down approach) visando a permitir ao arquivista um melhor entendimento da função, do processo e da atividade que gerou o documento.

O foco passa a ser externo e não mais interno. O que se deve levar em conta é o contexto e o processo do documento. Uma visão macro e não micro e limitada, segundo os teóricos pós-modernos da área.

Nesse cenário de reinterpretação, Terry Cook (2001) propõe algumas reformulações ou "novas formulações" para os conceitos e princípios mais importantes da área, visando a mudar o foco da disciplina - do registro para o processo que o gerou.

Entre os princípios e conceitos reformulados por Cook, destaca-se aqui, novamente, o Princípio da Proveniência, cujas características são agora a virtualidade e elasticidade, e que irá refletir nas funções e processos que levaram o criador a gerar um documento, em uma instituição ou organização dinâmica, que está em constante evolução, com pessoas e culturas diferentes, com abordagens e convenções distintas.

O princípio da ordem original também é discutido. Seu foco muda e manter os documentos físicos na mesma ordem em que foram produzidos, com o mesmo sistema de classificação, não é mais possível. Devem-se levar em conta os softwares e a intervenção desses na produção dos documentos e como eles são armazenados sem um meio físico. Segundo Cook (2001, p. 21, tradução nossa), "os documentos são combinados 
intelectualmente e funcionalmente, de formas diferentes, para objetivos diferentes, em lugares e horas diferentes, em vários tipos, por pessoas diferentes". A ordem irá refletir os múltiplos usos e não o arranjo físico. Um documento pode ser ordenando de várias maneiras, refletindo diferentes usos, para casos diversos.

Nesse contexto, o conceito de documento (record) é também reformulado e esse passa a ser dinâmico e não mais estático, e seus componentes - estrutura, conteúdo e contexto - não estão mais fixados em um meio unicamente físico, visto que são armazenados em forma de dados e por software diferentes.

Para a abordagem pós-moderna, o arquivo deixa de ser simplesmente o lugar onde estão alocados os documentos antigos utilizados pelos pesquisadores em suas consultas, para ser tornar dinâmico, um "arquivo sem paredes" como enuncia Cook (2001), existente na Internet, facilitando o acesso público a vários sistemas de record-keeping, tanto de documentos permanentes, como de documentos correntes.

Além desses conceitos propostos, o autor defende ainda a reformulação do conceito de avaliação - agora macroavaliação influenciando todo o processo de avaliação documental canadense, inclusive dos arquivos governamentais.

Considerando o contexto mais importante que o conteúdo do documento, Cook propõe uma avaliação maior (macroappraisal), em direção às funções e atividades dos criadores dos documentos e como os cidadãos interagem com eles.

A macroavaliação é o jeito canadense de fazer avaliação [...] ela avalia o valor social do contexto funcional-estrutural e da cultura do local de trabalho no qual os documentos são criados e utilizados por seus criadores, e a inter-relação dos cidadãos, grupos, organizações - 'o público' - com esse contexto funcional-estrutural (COOK, 2005, p. 101, tradução nossa).

Assim, a seleção documental deve estar baseada nos documentos que irão refletir essas interações e essas funções e atividades.

A proposta de Cook vai ao encontro da "redescoberta" da proveniência e das ideias pós-modernas, em que os documentos devem ser selecionados e avaliados com base na narratividade contextual de criação, ao invés do conteúdo, englobando tanto os documentos que representam a voz dos poderosos, como os que representam a voz dos "marginalizados".

Desse modo, tem-se "processo ao invés de produto, tornar-se ao invés de ser, dinâmico ao invés de estático, contexto ao invés de texto, refletir tempo e lugar, ao invés de verdades absolutas" (COOK, 2001, p. 24, tradução nossa), consistindo este, segundo o autor, o lema que deveria ser adotado pela Arquivística no novo século, como fundamento das concepções e reformulações propostas pela Arquivística Pós-Moderna. 


\subsection{Diplomática arquivística: a renovação do método diplomático}

A terceira abordagem tratada neste trabalho tem também os estudos desenvolvidos no Canadá, mas suas bases estão fundamentadas na Itália, a partir das discussões de Paola Carucci (1987) sobre os documentos contemporâneos, na década de 1980. Esses estudos correspondem à Diplomática Arquivística Contemporânea, uma superação da Diplomática Clássica, cujo foco recairá no estudo dos documentos e de suas funções.

Essa nova Diplomática encontra reflexo nos estudos sobre a "redescoberta" da proveniência realizados pelos autores do Canadá inglês e, consequentemente, na importância do estudo do contexto de produção e criação dos documentos contemporâneos.

Quando a Arquivística se depara com os novos formatos e as novas estruturas burocráticas no final da década de 1970, faz-se necessário a apropriação do método analítico-comparativo da Diplomática para que os arquivistas possam compreender o processo de produção dos registros em meio eletrônico e tradicional.

A incorporação da Diplomática pela Arquivística foi defendida primeiramente na década de 1960, com o estabelecimento de uma identificação entre o objeto de ambas as disciplinas, a partir dos estudos do arquivista francês Robert-Henri Bautier (1961). Na década de 1970, o Britânico Christopher Brooke também alertara aos arquivistas que uma mudança era necessária, convidando-os a reinventar a disciplina epropõe - estudo de uma Diplomática moderna que pudesse ser incorporada à Arquivística, para responder às novas demandas para a organização do conhecimento arquivístico no século XXI.

A proposta de Brooke (1970) é, então, ecoada na Europa e na América do Norte, respectivamente, a partir dos estudos de Paola Carucci, Francis Blouin, Hugh Taylor, Tom Nesmith e Luciana Duranti. Essa última desenvolveu seus trabalhos na Universidade de British Columbia, em Vancouver, onde estudou a fundo os princípios e métodos promulgados pela Diplomática Clássica, aplicando-os aos documentos contemporâneos.

O resultado dos estudos desses autores foi a "reinvenção" de uma disciplina que até então estava limitada ao estudo dos documentos históricos, desempenhando um binômio necessário com a Paleografia.

Dessa forma, a Diplomática, que antes se ocupava exclusivamente da espécie documental, agora, como ressalta Bellotto (2004, p. 53), é ampliada na direção da gênese documental e de sua contextualização nas atribuições, competências, funções e atividades da entidade geradora/acumuladora.

Nessa "nova" abordagem, o diálogo entre informação e documento de arquivo também encontra um espaço privilegiado, quando Bruno Delmas, professor de Diplomática Contemporânea da École Nationale des Chartes, estabelece uma relação direta da Diplomática com a "informação orgânica", reforçando as bases teóricas e metodológicas de aplicação do 
método diplomático aos documentos contemporâneos, propostas por Carucci. Segundo Delmas (1996, p. 440, tradução nossa):

[...] a noção de informação orgânica está implícita na noção de arquivos e fundos [...] Hoje parece evidente que o objeto da diplomática contemporânea é a informação orgânica [...] Qualquer informação, já no momento em que é criada ou recebida por um organismo ou individuo no curso de sua atividade, por esse ato isolado, é arquivística e compõe o fundo arquivístico de seu autor ou recebedor, com o mesmo status dos documentos mais antigos.

Essa relação ainda é pouco discutida pelos teóricos mais tradicionais da área. Para autores como Luciana Duranti (1996), a relação entre documento de arquivo e informação é visível; no entanto, ao abordar a Ciência da Informação, a autora admite desconhecer sua relação com a Arquivística, entendendo a primeira como uma "ciência autônoma e desinteressada" e com "princípios universalmente válidos" e, a segunda, como uma "disciplina matemática que estuda os meios tecnológicos de transportar informação" (ZINS, 2007, p. 337, tradução nossa).

Tal aspecto reforça um ainda tímido conhecimento mútuo do métier dessas duas áreas, na medida em que a concepção de CI de Duranti refere-se tão somente a uma abordagem tecnológica norte-americana, notadamente a partir dos estudos de Vannevar Bush (1945) e seguidores, acerca dos impactos tecnológicos na recuperação da informação científica, esquecendo-se, por exemplo, da longa trajetória da Documentação enquanto precursora da $\mathrm{CI}$, no que diz respeito aos sistemas informacionais e às atividades profissionais (RAYWARD, 1997), uma vez que Otlet referia-se a documento como algo abarcativo das dimensões biblioteconômica, arquivística e museológica.

Felizmente, a autora não faz a mesma separação da Arquivística e da Diplomática, ao publicar em 1987, uma série de artigos em seis partes, intitulada Diplomatics: new uses for na old science, no periódico arquivístico canadense Archivaria, na qual, influenciada pelas ideias de Carucci e refletindo seus estudos comparativos entre os documentos medievais e os documentos contemporâneos, a autora propõe novos usos para a disciplina, a partir da aplicação da crítica diplomática aos documentos de qualquer natureza.

Em seu trabalho, Duranti (1995) reaproxima a Diplomática e a Arquivística, construindo um discurso híbrido entre ambas, e propondo um novo método para a organização dos documentos. Esse novo método é o estudo da Tipologia documental, uma ferramenta segura para que o arquivista chegue à compreensão dos conjuntos documentais.

As fontes usadas para chegar à proveniência de um fundo e obter o conhecimento das funções são confiáveis, porém não suficientes. É necessário conhecer as atividades específicas de cada organismo e isso só é possível a partir das informações 
reveladas no próprio documento (DURANTI, 1995, p. 202, tradução nossa).

O método de análise proposto por Duranti (1995) pode ser aplicado com segurança aos documentos contemporâneos e ao estudo do processo de criação desses documentos. Por meio da análise tipológica, o arquivista pode identificar a função do documento e seu contexto de produção, focando sua análise na evidência, a partir de seus elementos formais, independentemente de outras fontes alternativas, como os organogramas e regimentos. A análise é feita de baixo para cima, a partir da peça documental (bottom-up diplomatic analysis), do documento individual.

O método engloba os fatos e atos, os procedimentos que os geraram, as pessoas que trabalharam na criação do documento e a função impregnada nesse documento.

Desse modo, "a análise do arquivista vai se deslocando desde o contexto documental imediato do material que examina até o amplo contexto funcional e, mais além, ao contexto sócio-cultural, isto é, desde a realidade do documento até a imagem dos criadores de documentos" (DURANTI, 1995, p. 188, tradução nossa).

A Diplomática proporciona a relação entre os criadores de documentos e os arquivistas, estabelecendo uma conexão entre o documento de arquivo e o sistema jurídico no qual foi criado.

Em seu trabalho "a autora retoma, portanto, a concepção de Bautier, de que ambas as disciplinas possuem o mesmo objeto, enfatizando que a Arquivística trabalha com o conjunto de documentos, e a Diplomática com o documento isolado" (TOGNOLI; GUIMARÃES, 2009, p. 30).

Com a aplicação do método diplomático, o arquivista é capaz de reconstruir todo o contexto de produção de um conjunto documental, a partir da peça documental, uma vez que as fontes utilizadas para reconstruir o percurso do documento, como os organogramas e regimentos, por exemplo, nem sempre serão suficientes.

Logo, os estudos realizados pela autora demonstram a eficácia da aplicação da crítica diplomática aos documentos contemporâneos e, com isso, os arquivistas passam a ver o método diplomático, ou estudo da Tipologia Documental, como uma ferramenta de suma importância para o conhecimento da documentação gerada no século XXI, uma vez que, como afirma Carucci (1987), "a análise das características formais e substanciais dos documentos é indispensável para identificar as séries, para reconduzir documentos singulares aos arquivos de origem, para entender em quais relações se encontram os documentos referentes a um mesmo procedimento conservados em séries distintas".

Como destacam Barros e Tognoli (2008, p. 11), à medida que as administrações vão ficando mais flexíveis e existe uma horizontalidade nas funções e competências, a estrutura das instituições vai ficando mais fragmentada. Dessa forma, a análise dos documentos como peças documentais que, de alguma maneira, remontam a essa estrutura 
esfacelada, é um caminho seguro para o desenvolvimento dos métodos arquivísticos.

Constata-se, portanto, que a Diplomática Contemporânea tem um locus investigativo privilegiado no Canadá, a partir dos estudos de Duranti, que (re) insere, ainda nesse contexto, os estudos de Sir. Hilary Jenkinson, reavivando os conceitos promulgados pelo autor no século passado.

A exposição de Duranti continha um rigor de análise além daquela desenvolvida na abordagem canadense da "neoprovenance" e ajudou a espalhar, com seus outros trabalhos e de seus estudantes, uma renovação neo-Jenkinsoniana cujo foco de atenção do arquivista recai no documento, especialmente em suas propriedades como evidência de atos e transações de seu criador (COOK, 1997, p. 36, tradução nossa).

O foco de Duranti no documento, enquanto prova de um ato e suas transações, é constantemente discutido entre os teóricos da área, visto que, para a autora, o documento - entendido aqui como record, ou registro - nada mais é do que uma prova de uma ação. Duranti (1994, p. 02, tradução nossa) define o documento de arquivo a partir da concepção clássica arquivística, como "qualquer documento criado (produzido ou recebido e reservado para ação ou referência) por uma pessoa física ou jurídica no curso de uma atividade como um instrumento ou subproduto de tal atividade".

Como consequência, a influência do pensamento jenkinsoniano é refletida nas características do documento de arquivo, defendidas pela autora e por sua proposta de uma Diplomática Contemporânea. Aqui, prevalecem as características de imparcialidade, autenticidade, neutralidade, inter-relacionamento e unicidade.

Dessa forma, os conceitos e princípios basilares da Arquivística, tais como o conceito de documento (record), o princípio da proveniência, o princípio da ordem original, o conceito de fundo e de Ciência Arquivística, propostos pela abordagem de Duranti (1996), também refletirão uma visão "livre" das influências políticas, sociais e culturais, e, portanto, mais descritiva e positivista do que funcional e pós-moderna.

Nesse contexto, uma vez que seus princípios são "universalmente válidos", a autora não propõe uma reinterpretação dos mesmos, e muito menos sua reformulação, como o fez Terry Cook (2001), baseando-se nos principais manuais arquivísticos para construir suas concepções, tais como o Manual dos Arquivistas Holandeses, o Manual of Archival Administration de Jenkinson, Archivistica de Casanova, Archivkunde de Brenneke e Modern Archives de Schellenberg.

A proposta colocada por Duranti $(1995 ; 1996)$ e, consequentemente, pela Diplomática Arquivística, é justamente a manutenção dos princípios e conceitos arquivísticos promulgados nos primeiros manuais, e a renovação 
do método e do objeto da Diplomática, para que, a partir dessa, os arquivistas consigam identificar e restabelecer o contexto de criação dos documentos contemporâneos, nos mais diversos meios e suportes, garantindo assim a manutenção da Arquivística no século XXI.

Portanto, destaca-se aqui, o importante papel do estudo da Tipologia Documental, e por consequência da Diplomática, para os novos contextos de produção documental, inclusive sua aplicação aos documentos eletrônicos, pois, com o advento das novas tecnologias de informação, os arquivistas se vêem despreparados para tratar da quantidade de documentos gerados pelos novos sistemas. Com isso, os profissionais da informação têm à frente mais um desafio: manter os registros criados em meio eletrônico inalterados, de forma a garantir seu acesso e sua autenticidade e fidedignidade nos sistemas em que foram gerados.

\section{Análise comparativa das abordagens emergentes}

A partir dessas novas questões colocadas, ocorre uma mudança de paradigma na Arquivística, como anunciado anteriormente, e os arquivistas se dão conta de que a disciplina não é mais capaz de resolver sozinha todos os problemas. É exatamente nesse contexto, que novas abordagens emergem, a fim de dar conta de uma realidade diferente e desconhecida.

É interessante destacar: as abordagens não são excludentes e há um possível diálogo entre elas, podendo, futuramente, integrar uma abordagem nova que aceite, por exemplo, a condição pós-moderna da Arquivística Funcional no concernente à reformulação dos princípios e conceitos básicos da disciplina, a integração dos records managers e dos archivists em um ciclo documental completo, como propõe a Arquivística Integrada, e o estudo do contexto a partir do documento, como propõe a Diplomática Arquivística.

Nesse sentido, será demonstrado a seguir, um quadro comparativo das abordagens apresentadas nesse trabalho, a fim de elucidar os pontos de conexão e os traços distintivos entre elas.

QUADRO 1 Quadro Comparativo das abordagens canadenses

\begin{tabular}{|c|c|c|c|c|c|}
\hline Abordagem & Fundamentação & $\begin{array}{l}\text { Características } \\
\text { da Arquivística }\end{array}$ & $\begin{array}{c}\text { Documento de } \\
\text { Arquivo }\end{array}$ & $\begin{array}{l}\text { Objeto de } \\
\text { estudo }\end{array}$ & Representantes \\
\hline $\begin{array}{l}\begin{array}{l}\text { Arquivística } \\
\text { Integrada }\end{array} \\
\text { Década de } \\
1980 \\
\text { Canadá } \\
\text { Francês }\end{array}$ & $\begin{array}{l}\text {-Baseada na } \\
\text { Arquivística Francesa } \\
\text { (arquivos históricos e } \\
\text { princípio da } \\
\text { proveniência) e na } \\
\text { Gestão de } \\
\text { documentos norte- } \\
\text { americana } \\
\text {-Identificação do } \\
\text { objeto de estudo } \\
\text { como "informação } \\
\text { registrada } \\
\text {-Enunciação do novo } \\
\text { paradigma, no final } \\
\text { do século XX. }\end{array}$ & $\begin{array}{l}\text {-Disciplina } \\
\text { integradora que } \\
\text { engloba a } \\
\text { criação, } \\
\text { tratamento, } \\
\text { conservação e } \\
\text { utilização de } \\
\text { documentos } \\
\text { ativos, semi- } \\
\text { ativos e } \\
\text { históricos } \\
\text {-Autônoma } \\
\text {-Interdisciplinar }\end{array}$ & $\begin{array}{l}\text {-Aqueles } \\
\text { produzidos ou } \\
\text { recebidos por } \\
\text { uma pessoa ou } \\
\text { organismo para } \\
\text { as suas } \\
\text { necessidades ou } \\
\text { o exercício das } \\
\text { suas atividades e } \\
\text { conservados pelo } \\
\text { seu valor de } \\
\text { informação geral } \\
\text {-Informação } \\
\text { orgânica }\end{array}$ & $\begin{array}{l}\text {-Conjunto } \\
\text { de } \\
\text { informações } \\
\text { orgânicas } \\
\text { (arquivos) }\end{array}$ & $\begin{array}{l}\text { Carol Couture } \\
\text { Jean-Yves } \\
\text { Rousseau } \\
\text { Jacques Ducharme } \\
\text { Michel Duchein } \\
\text { Louise Gagnon- } \\
\text { Arguin } \\
\text { André Bissonnette } \\
\text { Muriel Doyle- } \\
\text { Frenière } \\
\text { André Frenière }\end{array}$ \\
\hline
\end{tabular}




\begin{tabular}{|c|c|c|c|c|c|}
\hline $\begin{array}{l}\text { Arquivística } \\
\text { Funcional } \\
\text { Década de } \\
1980 \\
\text { Canadá inglês }\end{array}$ & $\begin{array}{l}\text {-Baseada no contexto } \\
\text { da Pós-Modernidade } \\
\text { e da enunciação do } \\
\text { novo paradigma } \\
\text { - Redescoberta do } \\
\text { Princípio da } \\
\text { Proveniência } \\
\text {-Reformulação dos } \\
\text { princípios basilares } \\
\text { da área } \\
\text {-Importância da } \\
\text { dimensão social do } \\
\text { documento - } \\
\text { paradigma social dos } \\
\text { arquivos }\end{array}$ & $\begin{array}{l}\text {-Disciplina em } \\
\text { constante } \\
\text { evolução, } \\
\text { mutável, e } \\
\text { dinâmica, capaz } \\
\text { de se adaptar às } \\
\text { novas realidades } \\
\text { de produção } \\
\text { documental } \\
\text {-Interdisciplinar }\end{array}$ & $\begin{array}{l}\text {-Entidade } \\
\text { construída e } \\
\text { mantida } \\
\text { socialmente } \\
\text {-Forma de poder } \\
\text { e de } \\
\text { manipulação } \\
\text {-Símbolos } \\
\text { construídos } \\
\text {-Dado conceitual } \\
\text {-Agente ativo e } \\
\text { dinâmico na vida } \\
\text { dos indivíduos, } \\
\text { organizações e } \\
\text { sociedade }\end{array}$ & $\begin{array}{l}\text {-Contexto } \\
\text { de produção } \\
\text { dos } \\
\text { documentos } \\
\text {-Análise dos } \\
\text { criadores do } \\
\text { documento } \\
\text {-Process- } \\
\text { bound } \\
\text { information }\end{array}$ & $\begin{array}{l}\text { Terry Cook } \\
\text { Hugh Taylor } \\
\text { Tom Nesmith } \\
\text { Laura Millar } \\
\text { David Bearman } \\
\text { Eric Ketelaar } \\
\text { Hans Booms } \\
\text { Verne Harris } \\
\text { Ciara Trace }\end{array}$ \\
\hline $\begin{array}{l}\text { Diplomática } \\
\text { Arquivística } \\
\text { Década de } \\
1980 \\
\text { Itália } \\
\text { Canadá Inglês }\end{array}$ & $\begin{array}{l}\text {-Baseada na } \\
\text { Diplomática Clássica } \\
\text {-Manuais de } \\
\text { Arquivística dos } \\
\text { séculos XIX e XX } \\
\text {-Estabelecimento de } \\
\text { uma identidade entre } \\
\text { documento de } \\
\text { arquivo e documento } \\
\text { diplomático proposto } \\
\text { por Bautier, na } \\
\text { década de 1960. } \\
\text {-Enunciação do novo } \\
\text { paradigma no final do } \\
\text { século XX. }\end{array}$ & $\begin{array}{l}\text {-Ciência neutra e } \\
\text { desinteressada } \\
\text { com princípios e } \\
\text { conceitos } \\
\text { universalmente } \\
\text { válidos, que } \\
\text { englobam a } \\
\text { natureza, as } \\
\text { características } \\
\text { dos arquivos e o } \\
\text { trabalho } \\
\text { arquivístico. } \\
\text {-Ciência livre das } \\
\text { influências } \\
\text { políticas, sociais } \\
\text { e culturais. } \\
\text {-Interdisciplinar }\end{array}$ & $\begin{array}{l}\text {-A prova de uma } \\
\text { ação } \\
\text {-Subproduto de } \\
\text { uma atividade } \\
\text { desenvolvida por } \\
\text { uma pessoa } \\
\text { física ou jurídica } \\
\text {-Imparcial } \\
\text {-Neutro } \\
\text {-Natural } \\
\text {-Inter- } \\
\text { relacionado } \\
\text {-Autêntico } \\
\text {-Único } \\
\text {-Inerentemente } \\
\text { verdadeiro }\end{array}$ & $\begin{array}{l}\text {-Documento } \\
\text { de arquivo } \\
\text {-Relação } \\
\text { entre o } \\
\text { documento } \\
\text { de arquivo e } \\
\text { o sistema } \\
\text { jurídico no } \\
\text { qual foi } \\
\text { criado. } \\
\text {-Informação } \\
\text { orgânica } \\
\text {-Forma } \\
\text { documental }\end{array}$ & $\begin{array}{l}\text { Luciana Duranti } \\
\text { Heather MacNeil } \\
\text { Bruno Delmas } \\
\text { Paola Carucci } \\
\text { Robert-Henri } \\
\text { Bautier }\end{array}$ \\
\hline
\end{tabular}

Fonte: Elaborado pelos autores.

Fica claro, a partir da análise do quadro apresentado, o momento em que a disciplina rompe com suas "verdades universais" e passa a enfrentar o problema da gestão da informação orgânica em meios eletrônicos.

Anteriormente, distinguiam-se apenas duas correntes no pensamento arquivístico mundial: (i) a Arquivística tradicional, desenvolvida na França e em outros países europeus, cuja preocupação recai, sobretudo, nos arquivos históricos; e (ii) a Gestão de documentos, desenvolvida nos Estados Unidos, a partir da Segunda Guerra Mundial, ocupando-se exclusivamente dos documentos correntes.

A década de 1980, representa a mudança de pensamento do arquivista relacionado aos conceitos e princípios sustentadores da disciplina, e sua preocupação com os novos meios de produção de documentos permite a emergência de um novo paradigma e, a partir dele, emergem abordagens complementares que possam dar conta desse novo contexto de produção documental, na tentativa de renovar e sustentar a disciplina no século XXI.

Embora as três abordagens tenham emergido sobre bases diversas, o momento de ruptura paradigmática encontra nelas um fator em comum, o que demonstra a força que os novos meios de comunicação e produção de informação exercem sobre a natureza da disciplina nesse novo milênio. 
Nesse sentido, faz-se necessário caracterizar a Arquivística como uma disciplina interdisciplinar, elemento observado em todas as abordagens. Sua atuação com a História, a Administração, a Informática e a Diplomática permite uma abrangência muito maior de seu contexto de atuação, além de possibilitar à disciplina mutação e dinamicidade, contribuindo sobremaneira, para sua evolução.

Essa evolução, por sua vez, se faz necessária, visto que o fato de se caracterizar a Arquivística como uma ciência "neutra" e "desinteressada", com "princípios universais", não condiz mais com a realidade pósmoderna, na qual a sociedade se encontra.

Aqui entra em discussão a natureza da área. A Arquivística Integrada e a Arquivística Funcional trabalham com o conceito de disciplina (científica), enquanto a Diplomática Arquivística, sofrendo influências do pensamento positivista dos neo-jenkinsonianos, irá tratá-la como uma ciência. No entanto, não cabe aqui delimitar sua natureza para isso seria necessária uma pesquisa específica - e, sim, estabelecer os elementos de diálogos entre as abordagens.

A integração de prática e teoria que circundam o ciclo vital dos documentos é um dos pilares para o que Lopes (1997, tradução nossa) chamou de Internacionalização da disciplina. A partir desta, há um maior desenvolvimento científico dos estudos, uma aproximação com outras áreas do conhecimento e uma possível aplicação universal de conceitos e metodologias, sem distinção de país ou cultura.

Essa universalização dota a disciplina de um status científico, uma vez que essa é uma característica comum a todas as disciplinas das ciências contemporâneas (LOPES, 1997, tradução nossa).

A Arquivística, como outras disciplinas, deverá sofrer as influências do pensamento pós-moderno no estabelecimento de sua natureza, objeto e objetivo.

Tradicionalmente fundamentada na História e na Diplomática, a Arquivística viu seu trabalho limitado durante um século, ao estudo dos documentos permanentes, mantidos em arquivos históricos. Após a Segunda Guerra Mundial, com a enunciação da gestão documental, os documentos ativos e semi-ativos passam a ser considerados objeto de estudo de outra área, dando lugar a uma ruptura no ciclo documental.

O restabelecimento no Canadá da Arquivística, enquanto uma disciplina integrada, levou, também, a uma nova conceituação e caracterização do documento de arquivo e do objeto de estudo da disciplina.

Quando os teóricos do Québec anunciam o conceito de informação orgânica em substituição ao documento de arquivo, um novo momento de ruptura acontece. Esse momento encontra uma interlocução na Arquivística Funcional e na Diplomática Arquivística, como pode ser observado no quadro.

É interessante destacar que, durante mais de um século de existência, enquanto disciplina, a Arquivística ainda não possui uma unidade de critério acerca das características do documento de arquivo. Não que isso seja um fator negativo, pelo contrário, mas é no mínimo 
curioso observar as diferenças propostas pelas abordagens estudadas nesse trabalho.

Desde o início, os documentos foram criados para servir de prova de um determinado fato, atestando deveres e comprovando direitos, e são identificados como objeto da Arquivística no final do século XIX, quando essa adquire o status de disciplina.

As bases para um entendimento dos documentos enquanto fontes históricas e provas de um fato, estão enraizadas no ideal filosófico de verdade, enunciado no século XVII que encontrou na investigação empírica um meio de estabelecer a verdade por meio de inferências, generalizações e probabilidades.

Esse ideal filosófico de verdade encontra lugar no racionalismo do século XVIII e no positivismo do XIX, este último influenciando, decisivamente, a constituição da Arquivística, enquanto área do saber. Nesse contexto, os padrões histórico e legal dessa época, foram absorvidos pela disciplina em sua teoria e metodologia e, segundo MacNeil (2001, p. 39), "permanecem incorporados no pensamento arquivístico e sustentam nossas suposições atuais sobre o que constitui um documento confiável e autêntico em geral".

As características "confiável" e "autêntico" estão intimamente ligadas às características "imparcialidade", "naturalidade" e "neutralidade", moldadas nos postulados de Jenkinson, que têm sido utilizadas para definir o conceito de um documento arquivístico ideal no século XXI, documento esse, concebido, redigido e construído em um contexto histórico, social e cultural diferente daquele encontrado nos séculos anteriores.

Nesse sentido, se a sociedade encontra-se agora em um contexto pós-moderno, onde as certezas e verdades absolutas deram lugar às rupturas e desconstruções, como poderá continuar afirmando que o documento de arquivo é um mero subproduto de uma atividade, desempenhada por uma pessoa física ou jurídica no decorrer de uma função? E que esse "subproduto" é imparcial, neutro e "nasce" naturalmente?

O pós-moderno busca rupturas, busca eventos em vez de novos mundos, busca o instante revelador depois do qual nada mais foi o mesmo, busca um "quando-tudo-mudou" (...), ou melhor, busca os deslocamentos e mudanças irrevogáveis na representação dos objetos e do modo como eles mudam (JAMESON, 2000, p. 13).

O instante revelador, apresentado por Jameson (2000), pode ser identificado na Arquivística, como a mudança de paradigma anunciada na área no final dos anos 1980. Após sua enunciação, a disciplina deve buscar um novo rumo, em direção a essa nova realidade e deve entender que seu objeto, de fato, mudou. 
O documento de arquivo passa a ser entendido como uma entidade social e culturalmente construída, na qual estão implicadas as relações de poder, onde mais de uma história pode ser contada. Esse novo "lugar" ocupa uma posição tendenciosa, e não está livre das influências sofridas em seu contexto de criação.

O modelo de "documento ideal", proposto nos estudos dos neojenkinsonianos, como os de Luciana Duranti, não pode mais ser absorvido como uma verdade absoluta por uma disciplina contemporânea, que se encontra em uma sociedade pós-moderna e que vai de encontro às metanarrativas e aos conceitos e métodos propostos nos séculos XIX e $X X$.

Claro que é necessário estabelecer as características documentais, como autenticidade e fidedignidade; no entanto, o arquivista deve ter em mente que, ao fazê-lo, está implicando suas próprias construções moldadas em um contexto particular.

Para os arquivistas, a teoria pós-moderna nos lembra o que nós já deveríamos saber, que os métodos para avaliar o valor de verdade dos documentos como prova estão fundados em um modo particular de olhar o mundo e em uma concepção particular dos documentos como um tipo de testemunho sobre o mundo. Os critérios que eles estabeleceram para determinar - que conta como verdade são produtos de escolhas históricas, culturais, e políticas e não esgotam todas as maneiras possíveis de olhar para o mundo ou para a relação entre os documentos e o mundo (MACNEIL, 2001, p. 45, tradução nossa).

Em um mundo pós-moderno, os arquivistas devem levar em conta as diversas narrativas que estão compostas em um documento. O que se vê não é a única história contada e, sim, uma das histórias que estão implicadas no documento. Eles devem ter em mente que estão moldando a herança documental da sociedade e que o documento desempenha um papel ativo e dinâmico nesse contexto.

A interlocução entre as abordagens pode ser observada também no objeto de estudo da Arquivística. É claro que o documento de arquivo continua a ter um papel importante nessas abordagens, pois ele não deixa de ser o instrumento e o registro de uma ação, no entanto, o papel central é dado à informação e ao seu processo de produção.

O contexto de produção dos documentos e a análise dos criadores é o principal foco da abordagem funcional. Estudar quem produz, por que e como produz, e quais as intenções por trás daquele documento produzido são a máxima do pensamento pós-moderno, logo, a máxima da Arquivística Funcional. O contexto por trás do texto. A análise do criador para o documento, e não do documento para o criador, como propõe a Diplomática Arquivística. 
Já segundo a abordagem diplomática, todo o contexto e o processo podem ser observados a partir do estudo da forma documental. Nesse sentido, ambas se diferenciam quanto aos meios - a primeira tem sua análise de cima para baixo (contexto-documento) e, a segunda, tem sua análise de baixo para cima (documento-contexto) - porém, independentemente do caminho escolhido, o arquivista conseguirá chegar ao mesmo lugar: na identificação do contexto de produção dos documentos e conseguirá proceder a uma organização arquivística baseada em princípios e conceitos válidos.

Outro fato interessante, já destacado aqui, é que embora todas as abordagens trabalhem com o conceito de informação orgânica, apenas a primeira abordagem (Arquivística Integrada) se vê inserida dentro da Ciência da Informação, o que demonstra uma carência também dos estudos relativos à informação enquanto objeto da Arquivística.

\section{Considerações finais}

Observa-se que a realidade arquivística canadense contrasta com as crescentes dificuldades encontradas pelos arquivistas nos últimos anos e, por essa razão, seu solo é terra fértil de pesquisa, desenvolvendo conhecimento teórico e metodológico para a organização e preservação do conhecimento arquivístico.

Quando Taylor (1987) enuncia uma mudança de paradigma da área, ele redefine a pesquisa e a prática na Arquivística que até então se desenvolviam. A partir de seus estudos, os arquivistas, em especial os canadenses, passam a ver a proveniência como um princípio muito mais revelador do que antes se imaginava.

As novas formas de produção documental e as tecnologias de informação permitem uma produção dinâmica, virtual, interativa e experimental de registros, sem precedentes. Os arquivistas passam a fazer parte dessa produção e devem trabalhar nessa direção, criando metodologias e padrões que assegurem a efetividade de seu trabalho. A antiga visão de Jenkinson não condiz mais com a realidade atual, uma vez que o arquivista não pode mais ser visto como um simples guardião dos documentos, imparcial e neutro. Nesse sentido, é necessária a emergência de abordagens que possam dar conta da nova realidade.

Desta feita, procurou-se evidenciar como o pensamento canadense tem colaborado na construção do conhecimento arquivístico, desempenhado um papel brilhante na construção de uma Arquivística Contemporânea, enunciando rupturas paradigmáticas na área, como fez Hugh Taylor (1987), reintegrando a disciplina e seu ciclo documental; como tem feito a Arquivística Integrada, reinterpretando princípios e conceitos e criando novas abordagens para as funções arquivísticas; como tem feito Terry Cook (2001) e a Arquivística Funcional; e desenvolvendo conhecimento teórico e metodológico para a criação e manutenção de documentos gerados eletronicamente em ambientes interativos, dinâmicos e experimentais, além de reintegrar métodos de antigas 
ciências para a construção de uma nova disciplina, como tem feito Luciana Duranti (1995).

Com base no estudo das abordagens apresentadas, destaca-se que a Arquivística Integrada e a Diplomática Contemporânea não apresentam, em nenhum momento, uma ruptura dos princípios e conceitos propostos desde o nascimento da Arquivística enquanto disciplina, pelo contrário. Essas abordagens contribuem para uma continuação e renovação da disciplina, incorporando, porém, novos elementos que possam garantir a ela uma sustentação no século XXI. Ao contrário, a Arquivística Funcional busca, por meio de rupturas, enriquecer e integrar a disciplina na realidade documental atual.

É importante ressaltar que, embora apresentem meios distintos, todas as abordagens buscam o mesmo fim: "garantir a organização do conhecimento arquivístico e a sustentação da disciplina em um momento de rupturas paradigmáticas e inovações tecnológicas" (TOGNOLI; GUIMARÃES, 2010, p. 411).

\section{Referências}

BARROS, T. H. B.; TOGNOLI, N. B. Tipologia documental e a formação discursiva. In: FÓRUM INTERNACIONAL DE ARQUIVOLOGIA, 1., João Pessoa. A revolução e o significado do conhecimento na Arquivologia, João Pessoa, 2008.

BAUTIER, R.. Leçon d'ouverture du cours de diplomatique à L'Ecole des chartes. Bibliothèque de l'Ecole des Chartes, p.194-225,1961,. Disponível em:

<http://scrineum.unipv.it/biblioteca/biblioteca-bautier.htm $>$. Acesso em: 05 mai. 2007.

BELLOTTO, H. L. Arquivos permanentes: tratamento documental. $2^{\mathrm{a}}$ ed. Rio de Janeiro: FGV, 2004.

BUSH, V. As we may think. Atlantic Monthly, v.176, n.1, p. 101-108, 1945.

CARUCCI, P. Il documento contemporaneo: Diplomatica e criteri di edizione. Roma: La Nuova Italia Scientifica, 1987.

COOK, T. What is past is prologue: a History of archival ideas since 1898, and the future paradigm shift. Archivaria, v. 43, p. 18-63, Spring 1997.

Archival science and postmodernism: new formulations for old concepts. Archival Science: International Journal on Recorded Information, v. 1, n. 1, p. 3-24, 2001.

. Macroappraisal in theory and practice: origins, characteristics, and implementation in Canada, 1950-2000. Archival Science, v. 5, p. 101$161,2005$.

COUTURE, C.; DUCHARME, J.; ROUSSEAU, J. L'archivistique a-t-elle trouvé son identité? Argus, v. 17, n. 2, p. 51-60, 1988. 
DELMAS, B. Manifesto for a contemporary diplomatics: from institutional documents to organic information. American Archivist, v. 59, p. 438-452, Fall 1996.

DURANTI, L. Diplomatica: usos nuevos para una antigua ciencia. Carmona, Sevilla: S\&V Ediciones, 1995.

- Archival Science. Encyclopedia of Library and Information Science, v. 59, p. 1-19, 1996.

DURANTI, L. Registros documentais contemporâneos como prova de ação. Estudos Históricos, v. 7, n. 13, p.49-64, 1994.

GUIMARÃES, J. A. C. Ciência da Informação, arquivologia e biblioteconomia: em busca do necessário diálogo entre o universo teórico e os fazeres profissionais. In: GUIMARÃES, J.A.C; FUJITA, M.S.L (Orgs.). Ensino e pesquisa em biblioteconomia no Brasil: a emergência de um novo olhar. Marília: Cultura Acadêmica e Fundepe, 2008. p. 33-43.

JAMESON, F. Pós-modernismo: a lógica cultural do capitalismo tardio. $2^{a}$ ed. São Paulo: Ática, 2000.

KETELAAR, E. Archivistic research saving the profession. American Archivist, v. 63, n. 2, p. 322-340, Fall 2000.

LOPES, L. C. Vers une archivistique internationale à l'êre de l'information. Archives, v. 29, n. 2, p. 45-64, 1997-1998.

MACNEIL, H. Archival studies in the Canadian Grain: the search for a Canadian Archival Tradition. Archivaria, n. 37, p. 134-149, 1994.

Trusting records in a postmodern world. Archivaria, v. 51, p. 4647, Spring 2001.

MILLAR, L. Discharging our debt: the evolution of the total archives concept in English Canada. Archivaria, n. 46, p. 103-146, 1998.

RAYWARD, W. B. The origins of Information Science and the International Institute of Bibliography/International federation for Information and Documentation (FID). Journal of theAmerican Society for Information Science, v. 48, n. 4, p. 289-300, 1997.

SMIT, J. W. Arquivística, biblioteconomia e museologia: o que agrega estas atividades profissionais e o que as separa? Revista Brasileira de Biblioteconomia e Documentação, v. 1, n. 2, p. 11-26, 2000.

TAYLOR, H. A. Transformation in the Archives: technological adjustment or paradigm shift? Archivaria, v. 25, p. 12-28, Winter 1987-88.

TOGNOLI, N. B. A contribuição epistemológica canadense para a construção da Arquivística Contemporânea. 2010. 120 f. Dissertação (Mestrado em Ciência da Informação) - Faculdade de Filosofia e Ciências, Universidade Estadual Paulista, Marília.

TOGNOLI, N. B.; GUIMARÃES, J.A.C. A Diplomática Contemporânea como base metodológica para a organização do conhecimento arquivístico: 
perspectivas de inovação a partir das idéias de Luciana Duranti. In: ROMERO, N. L. (Ed.; Org.). Nuevas perspectivas para la difusion y organización del conocimiento. Valência: Universidad Politécnica de Valencia, 2009. v. 1. p. 38-47.

TOGNOLI, N. B.; GUIMARÃES, J.A.C. Postmodern Archival Science and Contemporary Diplomatics: new approaches for archival knowledge organization. In: GNOLI, C.; MAZZOCCHI, F. (Eds.; Orgs.). Paradigms and conceptual systems in knowledge organization. Würzburg: Ergon Verlag, 2010. p. 405-411.

ZINS, C. Conceptions of Information Science. Journal of the American Society for Information Science and Technology, v. 58, p. 335-350, 2007. 